\title{
The Effect of the Affordable Care Act Preexisting Conditions Provision on Marriage
}

Matt Hampton *

Otto Lenhart ${ }^{\dagger}$

August 7, 2019

\begin{abstract}
:
This paper investigates the effect of the Affordable Care Act preexisting conditions provision on marriage. The policy was implemented to prevent insurers from denying insurance coverage to individuals with preexisting health conditions. We test whether the implementation of the provision led to decreases in marriage among affected adults. We add to earlier work on how marital behavior is influenced by spousal health insurance and examine for the presence of "marriage lock," a situation in which individuals remain married primarily for insurance. Using data from the Panel Study of Income Dynamics from 2009 to 2017 and estimating difference-indifferences models, we find that male household heads with preexisting conditions are 7.12 percentage points ( 8.9 percent) less likely to be married after the policy. Using information on insurance status prior to the policy change, we find significant reductions in marriage among individuals with preexisting conditions who were previously insured by spousal health insurance plans. The findings suggest that the inability to attain individual coverage and reliance on spousal insurance provided incentives to remain married before 2014 .
\end{abstract}

Keywords: Affordable Care Act; Preexisting Conditions; Health Insurance; Marriage

JEL Classifications: J12, I13, D1 


\section{Introduction}

In the United States employer-provided health insurance system, a substantial proportion of the insured are dependents. Under this system, eligibility for adults is often determined by marital status, which creates a situation in which individuals may rely on a spouse for health insurance coverage. Married people with poor health who are unable to work are likely to be particularly dependent on being covered by their partner's insurance plan. Because spousal health insurance coverage is an added benefit of marriage, the fear of losing health insurance might prevent some individuals from pursuing a divorce.

One of the major goals of recent health care reform within the U.S. was to reduce the proportion of uninsured individuals in the population. One particularly vulnerable subgroup of the population is the estimated 52 million adult Americans who have health conditions making them uninsurable under previous laws (Claxton et al., 2016). Prior to the Affordable Care Act (ACA), this group of people may have been charged higher premiums by insurance companies or even denied coverage altogether. For individuals with preexisting conditions, this not only created serious barriers to obtaining affordable health insurance, but it also increased the value of an insurance plan once procured.

The ACA preexisting conditions provision, which was implemented in 2010 for children and in 2014 for adults, prevents insurance companies from denying coverage or charging higher premiums to people with preexisting conditions. Prior to 2014, adults with preexisting conditions who were not able to attain affordable insurance coverage may have had to go without needed health care. While individuals with preexisting conditions who were covered by their spouse's plans might have had additional incentives to remain married, the 2014 ACA reform may have 
reduced their reliance on spousal coverage by increasing the availability of affordable health insurance for individuals with health issues.

This paper is the first to study the impact of the ACA preexisting conditions provision on the marital behavior of individuals with preexisting health conditions. The study contributes to the literature that examines how marriage decisions are influenced by policy incentives that affect health insurance coverage. It is motivated in part by Abramowitz (2016) who finds evidence that the ACA dependent coverage provision, which allows young adults to remain on parental health insurance plans until the age of 26 , led to a decrease in the likelihood of marriage and an increase in the probability of divorce among young adults. Abramowitz (2016) provides evidence that while spousal health insurance plans increase the value of marriage, being eligible to remain on parental plans reduces the incentive to remain married. We hypothesize that by reducing one's reliance on spousal health insurance coverage, the ACA preexisting conditions provision could have similar effects on individuals with health conditions.

To test the hypothesis that the ACA preexisting conditions provision may have affected marriage, we use longitudinal data from the Panel Study of Income Dynamics (PSID) to follow the same individuals over the years 2009 to 2017 and estimate difference-in-differences models containing individual-level fixed effects. Focusing on a sample of household heads with preexisting conditions prior to 2014 , we find that after policy implementation, individuals with such conditions are 7.12 percentage points less likely to remain married. This corresponds to an 8.9 percent reduction in marriage within the group. To provide evidence that individuals with preexisting conditions may have been particularly reliant on spousal insurance prior to the ACA, we show that there were significant reductions in marriage within a sample of individuals who were covered by a spousal plan before 2014. We believe that our findings provide an indication 
of "marriage lock," a situation in which a couple remains married primarily for one partner to maintain health insurance coverage that he or she may not be able to get otherwise. ${ }^{1}$

We conduct several falsification tests and show that the estimates are robust to a variety of different specifications. To alleviate concerns that using the stock of married people as the outcome may understate the effects of the policy (Abramowitz, 2016), we show that the effect is robust when using a measure of marriage flow as the dependent variable. Additionally, to provide evidence that the negative marriage effect is not driven by other provisions of the ACA such as dependent coverage or Medicaid expansion, we find that significant decreases in marriage also occurred among individuals living in non-Medicaid expansion states and that the effects are largest for those between the ages of 30 and 45 . In addition, we conduct an event study to examine annual treatment effects and provide evidence of parallel pre-treatment trends between the treatment and control groups. We find that negative marriage effects become larger in magnitude over time since the 2014 implementation, which could be related to the lengthy nature of divorces.

\section{Marriage and Health Insurance Coverage}

Gary Becker's model of marriage (Becker, 1973, 1974) is based on two assumptions: 1) each individual tries to find a partner who maximizes his or her well-being, where well-being is measured by the consumption of household-produced commodities, and 2) the marriage market is in equilibrium. The model shows that gains from marrying compared to remaining single are positively correlated with income, human capital, and relative differences in wages. Becker (1973) shows that a necessary condition for marriage is that total output of the marriage must

\footnotetext{
${ }^{1}$ Marriage lock is analogous to job lock, i.e., remaining at an employer primarily for insurance purposes.
} 
exceed the sum of maximum outputs of single individuals. Spousal health insurance coverage is a component of the value of marriage. A result of this could be that unhappily married people may decide to remain married because of fears that they will not be able to obtain insurance coverage on their own.

Abramowitz (2016) notes that the benefit of obtaining insurance coverage through marriage could impact both coupled and single individuals. For single individuals, an available spousal plan may induce individuals to marry since insurance makes marriage more attractive. Similarly, a wider availability of health insurance plans reduces dependence on spousal coverage for married individuals and may therefore make marriage less attractive. We hypothesize that in a pre-ACA world, individuals suffering from preexisting conditions were particularly influenced by these marriage channels. Our analysis investigates whether this widening of insurance options following implementation of the ACA reduced the likelihood of marriage among people with preexisting conditions.

Prior literature has established the link between health insurance coverage and marriage. Examining the role of marriage as an important factor for providing health care access, Pylypchuk and Kirby (2017) show that racial differences in marriage could explain existing disparities in health care access. Researchers have shown that unmarried women are less likely to be insured than married women (Bernstein et al., 2008; Harrington Meyer and Pavalko, 1996), and that divorce leads to losses of coverage among women (Zimmer, 2007; Lavelle and Smock, 2012) and increases in individually-owned private coverage (Peters et al., 2014). Results from a survey in 2008 among a nationally representative random sample of 2,003 adults suggest that insurance might be a determinant of a couple's decision to get married (Kaiser Family Foundation, 2008). Seven percent of survey respondents affirmed that a person in their 
household got married over the last year mainly to have access to health care benefits. Since individuals with preexisting conditions may have been worried about being denied coverage prior to the ACA, insurance could have played a large role in their marital decisions.

\section{Data}

Our study uses data from the Panel Study of Income Dynamics (PSID), a nationally representative longitudinal sample of households interviewed annually since 1968 and biannually since 1997. In our analysis, we follow the same individuals from 2009-2017, which provides us with three survey waves prior to and two waves after the 2014 policy implementation. ${ }^{2}$ The PSID gathers information reported by household heads, which by design are males within marriedcouple families and either males or females within single-individual homes.

Given that the focus of this study is to test for changes in marital behavior and due to the design of the PSID, we restrict the sample to focus on a group of male household heads. One advantage of the PSID is that it allows us to test whether behavior is affected differentially depending on whether the head of household or his partner has the preexisting condition. Given that the legal age of marriage in the U.S. is 18 , and individuals become eligible for Medicare at the age of 65 , we further restrict the sample to consist of individuals between the ages of 18 and 64 . Additionally, we exclude respondents with missing information on marital status. These restrictions leave our analysis with a sample of 10,047 individuals and 50,235 total observations.

To narrow the sample to a group of individuals that are likely affected by the preexisting conditions provision, we use responses to whether a doctor has ever diagnosed the survey participants with any of the following health conditions: stroke, heart attack, heart disease, lung

\footnotetext{
${ }^{2}$ The PSID is conducted biannually.
} 
disease, diabetes, cancer, and other serious chronic conditions including seizures, kidney disease, autoimmune disorder, Parkinson's disease, coronary problems, and bone disorder. In a policy brief on preexisting conditions in the U.S., Fehr et al. (2018) list the most common conditions that led to denial of insurance coverage prior to the ACA. The authors list all the mentioned conditions that are included in the PSID and used in our analysis. ${ }^{3}$ The main treatment group consists of individuals who report that they had at least one of the conditions in all three prepolicy survey years. This provides us with a treatment group of 1,351 individuals, for which we have 6,755 total observations. For the control group, we consider people who report that they have no health conditions in all years prior to the reform (8,696 individuals and 43,480 observations). ${ }^{4}$

Table 1 provides summary statistics for the treatment and control groups of the analysis. The statistics indicate that men forming the treatment group are 6.79 percentage points less likely to be married after policy implementation compared to the pre-policy survey years. Conversely, the likelihood of being married increases for members of the control group by 2.13 percentage points. The substantial decline in the share of men with preexisting conditions who are married after the policy is confirmed by Figure 1, which provides graphical evidence of changes in marital status between 2005 and 2017. While relatively similar trends in the likelihood of being married are noticeable for the two groups during the years prior to the policy, Figure 1 shows a stark decline in the likelihood of being married for individuals with preexisting conditions between 2013 and 2017.

\footnotetext{
${ }^{3}$ Fehr et al. (2018) also list mental disorders as a condition that led to denial of coverage. Unfortunately, the PSID does not include information about mental disorders. While we have no reason to believe that our results would differ if we included additional health conditions, the fact that we do not cover preexisiting conditions is a limitation of our study.

${ }^{4}$ In an alternative specification, we find qualitatively similar results using a treatment group of individuals who report having had at least one of the conditions in 2013 (3,503 individuals).
} 
The summary statistics in Table 1 show that treated household heads are older and less likely to work compared to those in the control group, while the two groups are relatively similar in terms of race, education, and total family income. The bottom of Table 1 shows statistics for the share of individuals in the treatment group suffering from various health conditions during the pretreatment period $(2009,2011$ and 2013). The most prevalent condition is diabetes (44.19 percent), while the share of individuals who have had a stroke, heart attack, cancer, or heart and lung diseases are substantially smaller.

\section{Methodology}

Our study exploits the ACA prohibition of denial based on preexisting conditions provision to test for the effects of the policy on marriage behavior. We employ a difference-in-differences (DD) framework to observe the average treatment effects on a group of individuals most likely affected by the policy implementation. The main treatment group consists of male household heads who report that they have been diagnosed with at least one serious health condition in all survey waves prior to the policy change $(2009,2011$, and 2013). In an alternative specification, individuals whose spouse had a preexisting condition throughout the pre-policy period form the treatment group. The control group consists of individuals who had no preexisting health conditions between 2009 and 2013. We estimate the following equation to obtain average treatment effects:

$$
\mathrm{Y}_{\text {ist }}=\beta_{0}+\beta_{1} \text { Treat }_{\mathrm{i}}+\beta_{2} \mathrm{X}_{\mathrm{ist}}+\delta_{\mathrm{DD}} \text { Post }_{\text {ist }} * \text { Treat }_{\mathrm{i}}+\lambda_{1} \text { Year }_{\mathrm{t}}+\lambda_{2} \text { State }_{\mathrm{s}}+\alpha_{\mathrm{i}}+\varepsilon_{\text {ist }},
$$

where $\mathrm{Y}_{\text {ist }}$ is an indicator that equals one if individual i living in state $\mathrm{s}$ at time $\mathrm{t}$ is married and zero if he is either unmarried, widowed, divorced or separated. Treat ${ }_{i}$ equals one if the individual

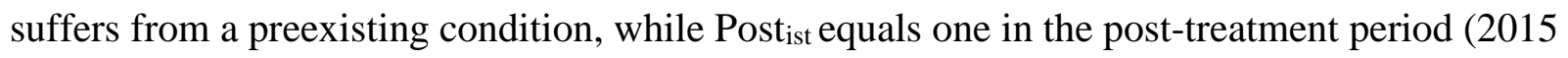
and 2017) and zero in the three pre-treatment years (2009, 2011, and 2013). The inclusion of the 
vector $\mathrm{X}_{\mathrm{ist}}$ controls for observable characteristics such as age, the number of children in the household, education, employment status, and total household income. ${ }^{5}$

The main parameter of interest is $\delta_{\mathrm{DD}}$, which captures the effect of the policy on the likelihood of being married. Equation (1) controls for year and state fixed effects to account for existing differences in marital status across time and space. One concern is that unobservable characteristics at the state level cause divorce to spike in certain states, and individuals making up the treatment group disproportionately live in these states. In additional models, we address this concern by including state-specific time trends. Finally, as the PSID contains repeated observations of individuals across time, equation (1) includes individual fixed effects $\left(\alpha_{\mathrm{i}}\right)$, which allows us to account for time-invariant heterogeneity across individuals. The use of longitudinal data reduces any potential bias due to changes in the composition of the sample before and after the policy. We estimate each of our DD specifications using linear probability models, with the standard errors clustered at the state level. ${ }^{6}$

While the main DD estimation for this study uses male household heads who had preexisting conditions throughout the pre-policy period as the treatment group, we further exploit the longitudinal nature of the PSID in two additional DD specifications. First, we narrow the sample to individuals who were married in all of the pre-treatment years (2009-2013). Again, the two treatment groups consist of households where either the head or the spouse has at least one health condition before the policy. This specification allows us to examine the effects of the policy on

\footnotetext{
${ }^{5}$ Additionally, due to concerns of endogeneity, we re-estimate our model when excluding employment status and total household income and find that the results remain unchanged.

${ }^{6}$ In additional variations to the standard DD model, we furthermore estimate propensity score matching DD models as well as an alternative DD model introduced by Mora and Reggio (2015), which identifies the effect of the policy using a fully flexible dynamic specification and includes a family of alternative parallel growth assumptions. Our main DD results are robust to these additional specifications. While these alternative DD estimates are not shown in the paper, they are available upon request.
} 
the flow of marriages more directly rather than the marriage stock. Using the stock of married people as an outcome could underestimate the magnitude of the effects of the provision (Abramowitz, 2016), and observing changes in marriage flow may capture policy effects more precisely. ${ }^{7}$ Second, we use information on insurance status and narrow our sample even further to household heads with preexisting conditions who are covered by spousal insurance plans in the pre-policy years. While the sample size is smaller, this specification estimates treatment effects on a group of individuals that is most likely affected by the policy, since they may be particularly reliant on their marriage for health insurance. Thus, the results from this specification are closer to treatment effects on the treated.

To specifically test whether the effects of the policy on marital decisions increased over time following its implementation in 2014, we augment equation (1) as below:

$$
\mathrm{Y}_{\mathrm{ist}}=\beta_{0}+\beta_{1} \text { Treat }_{\mathrm{ist}}+\beta_{2} \mathrm{X}_{\mathrm{ist}}+\sum_{t=2011}^{2017} \delta_{t} \text { Year }_{\mathrm{t}} * \text { Treat }_{\text {ist }}+\lambda_{1} \text { Year }_{\mathrm{t}}+\lambda_{2} \text { State }_{\mathrm{s}}+\alpha_{\mathrm{i}}+\varepsilon_{\mathrm{ist}},
$$

where the year indicators $\left(\right.$ Year $_{t}$ ) are interacted with the treatment indicator. The excluded reference category is the first sample wave of our analysis (2009). It seems reasonable to assume that the effects may increase over time after the policy implementation due to the often lengthy nature of divorce.

Besides differentiating between contemporaneous and lagged effects of the policy, estimating an event study furthermore allows us to test for the presence of similar trends in marital status during the pre-treatment years, which is the assumption governing any DD model. A statistically significant estimate of Year $_{t}$ pertaining to the years prior to the reform provides suggestive evidence of differential trends between the treatment and control groups (conditional on

\footnotetext{
${ }^{7}$ Similarly, Abramowitz and Dillender (2017) argue that using stock and flow outcomes may yield disparate results.
} 
covariates), and would violate the standard pre-treatment trends assumption. Additionally, we conduct a joint F-test among the pre-policy coefficients $\left(\delta_{2011}\right.$ and $\left.\delta_{2013}\right)$ to formally test for the prevalence of differential trends prior to 2014.

Finally, findings from the event study indicating that the effects of the provision on marital decisions are largest in 2017 would remove concerns that the any observed effects in the main analysis are driven by other events that occurred during our study period. One concern would be that the aftermath of the Great Recession differentially impacted the lives of individuals with and without preexisting conditions. Given that the last year of our analysis is 2017, which is nearly a decade after the onset of the Great Recession, an estimation of annual treatment effects may provide evidence that these that macroeconomic conditions are not driving our main results. In addition to estimating alternative DD models, we conduct several robustness checks. We run two additional specifications that account for the ACA Medicaid expansions that took place in 26 states and DC in 2014, which is the same year as the preexisting conditions provision for adults. ${ }^{8}$ We separately examine the impact of our policy change on marriage behavior of individuals with preexisting conditions in states that expanded Medicaid and the 24 states that did not. If Medicaid expansion is driving differences in marriage rates between individuals with and without preexisting conditions, we would expect no changes in marital status in states that did not expand Medicaid.

Another ACA provision that could have affected marital behavior is the 2010 dependent coverage mandate. Abramowitz (2016) provides evidence that the mandate reduced marriage

\footnotetext{
${ }^{8}$ The states that expanded Medicaid in 2014 are: Arizona, Arkansas, California, Colorado, Connecticut, Delaware, District of Columbia, Hawaii, Illinois, Iowa, Kentucky, Maryland, Massachusetts, Michigan, Minnesota, Nevada, New Hampshire, New Jersey, New Mexico, New York, North Dakota, Ohio, Oregon, Rhode Island, Vermont, Washington, and West Virginia.
} 
rates among young adults. While the policy examined in our study was implemented four years later, any observed effects might still be related to the dependent coverage mandate. To empirically test for whether the dependent coverage mandate is driving observed marriage effects, we re-estimate our main DD model for four different age groups. If the 2010 dependent coverage provision drives our results, we would expect to find larger effects for individuals below the age of 26 .

We also check whether the effects differ between people who were covered by their own employer-sponsored insurance and those that were not prior to 2014. As the policy is most likely to impact individuals that are unable to attain their own employer-sponsored insurance coverage, finding larger effects for those without this form of coverage would provide additional evidence that any observed effects are driven by the preexisting conditions provision.

To provide additional validity to our main findings, we estimate a falsification test utilizing a measure of self-reported health. A potential concern is that individuals with preexisting conditions are inherently different than those without, and perhaps it is the worsening of one's condition that eventually leads to a divorce. To mitigate concerns that sick people may be more likely to divorce than those that are healthy and it is not the preexisting conditions provision itself that drives the marriage reduction, we limit the sample to a group of individuals who have no preexisting conditions but have poor self-reported health. A significant finding that marriage dropped among this subgroup would be indication that it is not the preexisting conditions policy driving the results, but merely differences in health.

Finally, in three placebo tests, we re-estimate our main analysis for the time periods 2003-2009, 2005-2011 and 2007-2013 and create artificial treatment indicators. None of these time periods had changes in policy directly targeting the insurance needs of individuals with preexisting 
conditions. Thus, if estimates using these artificial treatment indicators are statistically significant, it may be indication that our main results are spuriously driven by other changes that differentially affected individuals with and without preexisting health issues.

\section{Results}

Table 2 presents the main DD estimates from our analysis. Panel A shows the main results obtained from the sample of male household heads. When including all fixed effects and controls, we find that the policy reduced the likelihood of being married among male household heads with preexisting conditions by 7.12 percentage points $(\mathrm{p}<0.01)$. This corresponds to a 8.9 percent reduction compared to the baseline mean (0.802). We find that the results remain unchanged when adding state-specific time trends. ${ }^{9}$ Panel A also shows that the policy reduced the likelihood of being married by 4.87 percentage points for household heads whose spouse had a preexisting condition in the survey years prior to $2014(\mathrm{p}<0.01)$. This suggests the policy affected marital decisions of households independent of which partner had the preexisting condition. In other specifications, shown in Appendix Table A1, we include additional controls and show that the results are not driven by either marriage or health history. We find that the results remain almost unchanged when including controls for marriage length, the number of marriages, as well as the age when the preexisting condition first occurred. ${ }^{10}$

In Panel B, we narrow the sample to individuals who were married throughout the pre-policy period to test whether the flow of marriages was impacted by the reform. Again, we find

\footnotetext{
${ }^{9}$ Six states (Maine, Massachusetts, New Jersey, New York, Vermont, and Washington) did not request detailed information about a person's medical history when they tried to purchase insurance prior to the ACA. We estimated our main model excluding these states and found a decline in the likelihood of being married of 7.24 percentage points $(\mathrm{p}<0.01)$, which is almost identical to the main result.

${ }^{10}$ In additional specifications, we exclude people in the control group whose spouse has at least one preexisting condition at some point during our study. The results remain unchanged and are available upon request.
} 
negative and statistically significant effects on the likelihood of remaining married among household heads with health conditions as well as for those whose spouses had preexisting conditions. Finding consistent results using both stock and flow outcome variables provides further evidence that the policy altered the marital behavior of individuals.

Finally, we narrow the sample in Panel $\mathrm{C}$ to household heads covered by spousal insurance plans in the years prior to 2014. As they would likely have been reliant on the marriage to attain health insurance, individuals with preexisting conditions within this subsample are those most directly impacted by the policy. In the full specification, and despite a low number of observations and potential issues with statistical power (313 treated individuals), we find a 4.12 percentage point decline $(\mathrm{p}<0.05)$ in the likelihood of being married among this group. This further suggests that the ability to obtain insurance coverage independently of one's partner influenced decisions to remain married. To further examine the flow of marriages, we also estimate the effects of the policy change on divorce directly. Appendix Table A2 shows a 3.28 percentage point increase $(\mathrm{p}<0.01)$ in being divorced among individuals in the treatment group, which suggests that the main findings in Table 2 are a combination of both a decrease in entry to marriage and an increase in exit. $^{11}$

Table 3 provides estimates for immediate and medium-run effects of the policy by showing the coefficients on the interaction terms between the treatment group and year dummies (equation 2). The results suggest that the observed effects, while negative and statistically significant in both post-policy years, became substantially larger in 2017. This is in line with the fact that divorce

\footnotetext{
${ }^{11}$ Additionally, we estimate ordered logit models using all five categories of marital status as the outcome variable. In line with the results shown in Appendix Table A2, we find a 6.50 percentage point decrease in being married and a 1.56 percentage point of being divorced (both $\mathrm{p}<0.01$ ). The ordered logit results are not included in the paper but are available upon request.
} 
can be lengthy and takes ample time before processed. Additionally, it may take some time before individuals become aware of and develop an understanding of the policy. The observed treatment effects are 5.06 percentage points in $2015(\mathrm{p}<0.05)$ and 9.26 percentage points in 2017 $(\mathrm{p}<0.01)$.

The causal effect of the policy in a DD framework depends on the assumption that trends in the dependent variable between treatment and control groups would have remained similar in the absence of the policy. The coefficients on the interaction terms for the likelihood of being married prior to the reform (2011 and 2013) are small and statistically insignificant. The joint Ftest of the pre-treatment coefficients confirms (at the 1 percent level) that there were no differential trends between the two groups before 2014. For additional clarity, we plot the main coefficients of Table 3 in Figure 2, along with 95 percent confidence interval bounds.

Table 4 provides several additional DD estimates testing the robustness and validity of our findings. Panel A presents results for individuals by pre-policy insurance status. The results suggest that our main findings are driven by individuals with no employer-sponsored insurance prior to 2014. As this is a group with no insurance coverage through an employer, they may be particularly reliant on spousal coverage. Among this group, we find a reduction in the likelihood of being married of 11.51 percentage points $(\mathrm{p}<0.01)$. Among individuals previously covered by employer-sponsored insurance, a group that is likely not dependent on spousal coverage, the estimated coefficient is small and statistically insignificant. These results are in line with our estimates from Table 2 that show significant changes in marriage among individuals previously covered by spousal insurance plans.

Next, we examine whether the 2014 Medicaid expansions and the 2010 dependent coverage mandate are driving the results. When separately testing the effect on marriage in states that 
expanded Medicaid in 2014 and those that did not, we find statistically significant reductions in marriage for both groups (Panel B). While the effect is larger in magnitude in states that expanded Medicaid, which indicates that access to Medicaid also impacts marital decisions, a significant finding in non-expansion states suggests that Medicaid changes are not the primary driver of the main results.

Panel C provides treatment effects for four age groups. While our results suggest that marriage is affected across all groups (all $\mathrm{p}<0.01$ ), the largest result is found for individuals between ages 30 and 45, and the smallest is among young adults between 18 and 26. Similar to findings from the event study, Panel C provides additional evidence that the results are driven by the 2014 preexisting conditions provision and not by the dependent coverage provision.

Panel D shows estimates for the three placebo tests using different periods as treatment indicators. The results from these models show that using artificial policy indicators leads to no effects on marriage behavior of individuals with preexisting conditions, which further suggests that the 2014 policy is driving our main findings.

Finally, Panel E presents results of the falsification test in which individuals without preexisting conditions but poor self-reported health are assigned to the treatment group, while individuals with fair or better health and no health conditions form control group. Consistent with the fact that these "treated" individuals should be unaffected by the ACA preexisting conditions provision, we do not find a statistically significant marriage effect among this group.

\section{Conclusion}

The results of our analysis indicate that the ACA preexisting conditions provision increased marital dissolution among individuals with preexisting conditions. Our main estimate indicates 
that male household heads with preexisting conditions are 8.9 percent less likely to remain married after the change in policy. We find negative effects among individuals with preexisting conditions who had no employer-sponsored coverage of their own and those covered by spousal insurance, groups that may be particularly reliant on marriage to attain insurance. We show that the estimates are robust across a variety of specifications and robustness checks. To mitigate concerns that findings are driven by other provisions of the ACA such as dependent coverage or Medicaid expansion, we conduct subgroup analyses to show that effects are not driven by young adults and are not unique to those living in Medicaid expansion states.

Our estimates provide evidence that individuals with health conditions may have been particularly reliant on marriage prior to the ACA since insurance companies were able to deny them coverage. We believe that the results are an indication of marriage lock, i.e., remaining in a marriage primarily for health insurance purposes. The magnitude of our findings is comparable with previous estimates of the effects of insurance access and changes in policy on marriage behavior. Abramowitz (2016) finds that the dependent coverage mandate decreased marriage rates by 8.8 to 9.3 percent among young adults, while Chen (2017) estimates a 7 percent increase in the number of divorces among individuals with spousal insurance coverage upon achieving Medicare eligibility at age 65.

By preventing insurers from denying coverage to individuals with preexisting conditions, the ACA may have added a level of relationship flexibility for people with health conditions. By freeing individuals from concerns that they may be denied coverage or charged higher premiums, the preexisting conditions provision decreases the benefit of marriage by making spousal insurance coverage less valuable. While likely not having an impact on the average person, the policy has the potential to influence marital decisions of those with preexisting conditions. Given 
pre-ACA laws, individuals with preexisting conditions are most susceptible to marriage lock since the value of a spousal health insurance plan is amplified due to fears of being denied coverage elsewhere.

Marriage lock among individuals with chronic conditions is a topic that is under-studied, and this paper offers both a better understanding of the insurance struggles of people with preexisting conditions and new evidence of how health care policy impacts marriage. Given that a substantial portion of the U.S. population suffers from a preexisting condition, it remains important to develop a better understanding of how this group is affected by health care policy. Researchers should continue to examine potentially unintended effects of the ACA and similar changes in policy to better understand the welfare implications of such reforms.

\section{References}

Abramowitz, J. (2016). Saying “I Don't: The Effect of the Affordable Care Act Young Adult Provision on Marriage. Journal of Human Resources, Vol. 51 (4): 933-960.

Abramowitz, J., \& Dillender, M. (2017). Considering the Use of Stock and Flow Outcomes in Empirical Analyses: An Examination of Marriage Data. Unpublished manuscript.

Becker, G. S. (1973). A Theory of Marriage: Part I. Journal of Political Economy, Vol. 81 (4): $813-46$.

Becker, G. S. (1974). A Theory of Marriage: Part II. Journal of Political Economy, Vol. 82 (2): S11-S26.

Bernstein, A. B., Cohen, R. A., Brett, K. M., \& Bush, M. A. (2008). Marital Status Is Associated with Health Insurance Coverage for Working-Age Women at All Income Levels, 2007. NCHS Data Brief, No. 11. Hyattsville, MD: National Center for Health Statistics.

Chen, T. (2017). Health Insurance Coverage and Marriage Behavior: Is there Evidence of Marriage-Lock? Working Paper. https://econ.uconn.edu/wpcontent/uploads/sites/681/2017/02/marriage_lock_tianxu_chen_201701.pdf 
Claxton, G., Cox, C., Levitt, L., \& Pollitz, K. (2016). Pre-existing Conditions and Medical Underwriting in the Individual Insurance Market Prior to the ACA. The Henry J. Kaiser Family Foundation, Policy Brief. https://www.kff.org/health-reform/issue-brief/pre-existing-conditionsand-medical-underwriting-in-the-individual-insurance-market-prior-to-the-aca/

Fehr, R., Damico, A., Levitt, L., Claxton, G., Cox, C., Pollitz, K. (2018). Mapping Pre-existing Conditions across the U.S. The Henry J. Kaiser Family Foundation, Policy Brief. https://www.kff.org/health-reform/issue-brief/mapping-pre-existing-conditions-across-the-u-s/ Harrington Meyer, M., \& Pavalko, E. K. (1996). Family, Work, and Access to Health Insurance among Mature Women. Journal of Health and Social Behavior, Vol. 37: 311-325.

Kaiser Family Foundation (2008). Rush to the Altar? The Henry J. Kaiser Family Foundation, Data Note, Kaiser Public Opinion. https://kaiserfamilyfoundation.files.wordpress.com/2013/01/7773datanote.pdf Lavelle, B., \& Smock, P. J. (2012). Divorce and Women's Risk of Health Insurance Loss. Journal of Health and Social Behavior, Vol. 53 (4): 413-431.

Mora, R., \& Reggio, I. (2015). Didq: A Command for Treatment-Effect Estimation under Alternative Assumption. Stata Journal 15, Vol. 3: 796-808.

Peters, H. E., Simon, K., \& Taber, J. R. (2014). Marital disruption and health insurance. Demography, 51(4):1397-1421.

Pylypchuk, Y., \& Kirby, J. B. (2017). The Role of Marriage in Explaining Racial and Ethnic Disparities in Access to Health Care for Men in the US. Review of Economics of the Household, Vol. 15: 807-832.

Zimmer, D. M. (2007). Asymmetric Effects of Marital Separation on Health Insurance among Men and Women. Contemporary Economic Policy, Vol. 25 (1): 92-106. 


\begin{tabular}{|c|c|c|}
\hline & Treatment Group & Control Group \\
\hline \multicolumn{3}{|l|}{ Married } \\
\hline \multirow[t]{2}{*}{ Pre } & 0.8018 & 0.7386 \\
\hline & $(0.3987)$ & $(0.4394)$ \\
\hline \multirow[t]{2}{*}{ Post } & 0.7339 & 0.7599 \\
\hline & $(0.4420)$ & $(0.4272)$ \\
\hline \multirow[t]{2}{*}{ Age } & 46.62 & 39.01 \\
\hline & $(10.66)$ & $(10.26)$ \\
\hline \multirow[t]{2}{*}{ Working } & 0.6836 & 0.8679 \\
\hline & $(0.4651)$ & $(0.3386)$ \\
\hline \multirow[t]{2}{*}{ \# Children in $\mathrm{HH}$} & 1.0801 & 1.4913 \\
\hline & $(1.2649)$ & $(1.4038)$ \\
\hline \multirow[t]{2}{*}{ White } & 0.6494 & 0.6258 \\
\hline & $(0.4772)$ & $(0.4839)$ \\
\hline \multirow[t]{2}{*}{ Black } & 0.2811 & 0.3002 \\
\hline & $(0.4496)$ & $(0.4583)$ \\
\hline \multirow[t]{2}{*}{ Other race } & 0.0694 & 0.0741 \\
\hline & $(0.2542)$ & $(0.2619)$ \\
\hline \multirow[t]{2}{*}{$<12$ years of education } & 0.1427 & 0.1453 \\
\hline & $(0.3498)$ & $(0.3524)$ \\
\hline \multirow[t]{2}{*}{12 years of education } & 0.3093 & 0.2836 \\
\hline & $(0.4623)$ & $(0.4507)$ \\
\hline \multirow[t]{2}{*}{$>12$ years of education } & 0.5480 & 0.5711 \\
\hline & $(0.4977)$ & $(0.4949)$ \\
\hline \multirow[t]{2}{*}{ Total Household Income } & $\$ 86,049.04$ & $\$ 87,631.49$ \\
\hline & $(85,193.24)$ & $(66,974.33)$ \\
\hline \multirow[t]{2}{*}{ Stroke (pre) } & 0.0780 & - \\
\hline & $(0.2682)$ & \\
\hline \multirow[t]{2}{*}{ Heart attack (pre) } & 0.1411 & - \\
\hline & $(0.3481)$ & \\
\hline \multirow[t]{2}{*}{ Heart disease (pre) } & 0.1334 & - \\
\hline & $(0.3400)$ & \\
\hline \multirow[t]{2}{*}{ Lung disease (pre) } & 0.1174 & - \\
\hline & $(0.3219)$ & \\
\hline \multirow[t]{2}{*}{ Diabetes (pre) } & 0.4419 & - \\
\hline & $(0.4967)$ & \\
\hline \multirow[t]{2}{*}{ Cancer (pre) } & 0.1358 & - \\
\hline & $(0.3427)$ & \\
\hline \multirow[t]{2}{*}{ Other serious condition (pre) } & 0.3684 & - \\
\hline & $(0.4824)$ & \\
\hline $\mathrm{N}$ & 6,755 & 43,480 \\
\hline
\end{tabular}


Table 2: Effects of the Policy Change on Marital Status

Panel A: All male household heads

Likelihood of being married

$\mathbf{N}$

Has a condition

$$
\begin{array}{cccc}
-0.0872 * * * & -0.0712 * * * & -0.0701 * * * & 50,235 \\
(0.0168) & (0.0159) & (0.0168) &
\end{array}
$$

Sample Mean

0.8018

Spouse has a condition

$$
\begin{array}{ccc}
-0.0676 * * * & -0.0487 * * * & -0.0461 * * * \\
(0.0157) & (0.0165) & (0.0161)
\end{array}
$$

0.9240

Sample Mean

Panel B: Male household heads

married between 2009 and 2013

Has a condition

$$
\begin{array}{cccc}
-0.0266 * * & -0.0270 * * * & -0.0281 * * * & 30,512 \\
(0.0105) & (0.0102) & (0.0103) &
\end{array}
$$

Spouse has a condition

$$
\begin{array}{cccc}
-0.0375 * * * & -0.0349 * * * & -0.0364 * * * & 28,867 \\
(0.0093) & (0.0091) & (0.0087) &
\end{array}
$$

Panel C: Male household heads covered by spousal ESI prior to policy

Has a condition

$$
\begin{array}{cccc}
-0.0504 * * * & -0.0412 * * & -0.0424 * * & 9,513 \\
(0.0164) & (0.0165) & (0.0173) &
\end{array}
$$

Fixed effects

Control variables

$\mathrm{X}$

$\begin{array}{ll}\mathrm{x} & \mathrm{x} \\ \mathrm{x} & \mathrm{x} \\ & \mathrm{x}\end{array}$

State-specific time trends

Robust standard errors, clustered by state, are shown in parentheses. The control variables include age, race, education, employment status and household income. $* \mathrm{p}<0.10, * * \mathrm{p}<0.05, * * * \mathrm{p}<0.01$. 


\section{Likelihood of being married}

Treat*2011

Treat*2013

Treat*2015

Treat*2017

$\begin{array}{ccc}-0.0067 & 0.0008 & 0.0015 \\ (0.0160) & (0.0174) & (0.0173)\end{array}$

$\begin{array}{lll}-0.0165 & -0.0021 & -0.0009\end{array}$

$\begin{array}{lll}(0.0188) & (0.0194) \quad(0.0195)\end{array}$

$\begin{array}{ccc}-0.0700 * * * & -0.0506 * * & -0.0492 * * \\ (0.0201) & (0.0201) & (0.0201)\end{array}$

$-0.1195 * * * \quad-0.0926 * * * \quad-0.0906 * * *$

$\begin{array}{lll}(0.0263) & (0.0260) & (0.0263)\end{array}$

$\mathrm{X}$

$\mathrm{X} \quad \mathrm{X}$

$\mathrm{X} \quad \mathrm{X}$

Control variables

State-specific time trends

Observations
50,235 $\mathrm{x}$

50,235

Robust standard errors, clustered by state, are shown in parentheses. The estimates are compared to the omitted year 2009. The control variables include age, race, education, employment status and household income.

$* \mathrm{p}<0.10, * * \mathrm{p}<0.05, * * * \mathrm{p}<0.01$. 


\begin{tabular}{|c|c|c|c|}
\hline & DD Effect & $\begin{array}{l}\text { Sample } \\
\text { Mean }\end{array}$ & $\mathrm{N}$ \\
\hline \multicolumn{4}{|l|}{ Panel A: Pre-2014 Insurance Status } \\
\hline Employer-Sponsored Coverage & -0.0152 & 0.9152 & 17,577 \\
\hline No Employer-Sponsored Coverage & $\begin{array}{c}(0.0134) \\
-0.1151 * * * \\
(0.0286)\end{array}$ & 0.6826 & 19,103 \\
\hline \multicolumn{4}{|l|}{ Panel B: ACA Medicaid Expansions } \\
\hline Expansion States & $\begin{array}{c}-0.1099 * * * \\
(0.0252)\end{array}$ & 0.8192 & 24,497 \\
\hline Non-Expansion States & $\begin{array}{c}-0.0391 * * \\
(0.0184)\end{array}$ & 0.7842 & 25,355 \\
\hline \multicolumn{4}{|l|}{ Panel C: Age } \\
\hline $18-26$ & $\begin{array}{c}-0.0338 * * * \\
(0.0118)\end{array}$ & 0.4270 & 4,002 \\
\hline $27-29$ & $\begin{array}{c}-0.0547 * * * \\
(0.0114)\end{array}$ & 0.7412 & 3,621 \\
\hline $30-45$ & $\begin{array}{c}-0.0961 * * * \\
(0.0059)\end{array}$ & 0.7694 & 20,200 \\
\hline $46-64$ & $\begin{array}{c}-0.0430 * * * \\
(0.0051)\end{array}$ & 0.8386 & 13,840 \\
\hline \multicolumn{4}{|l|}{ Panel D: Placebo Tests } \\
\hline Pre: 2003-2005, Post 2007-2009 & $\begin{array}{c}0.0056 \\
(0.0040)\end{array}$ & 0.8708 & 40,432 \\
\hline Pre: 2005-2007, Post 2009-2011 & $\begin{array}{l}-0.0011 \\
(0.0031)\end{array}$ & 0.9388 & 42,391 \\
\hline Pre: 2007-2009, Post 2011-2013 & $\begin{array}{c}0.0009 \\
(0.0034)\end{array}$ & 0.8394 & 44,822 \\
\hline Panel E: Falsification Test & & & \\
\hline Poor health status as treatment indicator & $\begin{array}{l}-0.0216 \\
(0.0586)\end{array}$ & 0.4815 & 36,133 \\
\hline
\end{tabular}

Robust standard errors, clustered by state, are shown in parentheses. $* \mathrm{p}<0.10, * * \mathrm{p}<0.05, * * * \mathrm{p}<0.01$. 